\title{
The UAE's Foreign Assistance Policy and Its Contributions to the Sustainable Development Goals
}

\author{
Bader Almatrooshi \\ Ministry of Foreign Affairs and International Cooperation of the United Arab Emirates, Abu Dhabi, United Arab Emirates \\ Email: jessica.pena@mofaic.gov.ae
}

How to cite this paper: Almatrooshi, B. (2019). The UAE's Foreign Assistance Policy and Its Contributions to the Sustainable Development Goals. Open Journal of Political Science, 9, 669-686. https://doi.org/10.4236/ojps.2019.94041

Received: September 17, 2019

Accepted: October 28, 2019

Published: October 31, 2019

Copyright $\odot 2019$ by author(s) and Scientific Research Publishing Inc. This work is licensed under the Creative Commons Attribution International License (CC BY 4.0).

http://creativecommons.org/licenses/by/4.0/

\begin{abstract}
The United Arab Emirates (UAE) stands out as one of the top donors worldwide based on its contributions compared to its Gross National Income (GNI). An insight to UAE's Foreign Assistance Policy, the current status of UAE's cooperation to International Development and the country's Official Development Assistance (ODA) to the Sustainable Development Goals (SDGs) will be determinant in order to understand the relations with the Caribbean region and the prospects for future collaboration.
\end{abstract}

\section{Keywords}

Foreign Policy, Foreign Assistance Policy, ODA, SDGs, International Development, Caribbean

\section{Introduction}

His Highness the late Sheikh Zayed Bin Sultan Al Nahyan, founding father of the United Arab Emirates, claimed that the fortune granted to the UAE should be shared with the rest of the humanity (Ministry of Foreign Affairs and International Cooperation of the United Arab Emirates, 2017a). Currently, the United Arab Emirates (UAE) stands out as the top donor worldwide based on its contributions compared to its Gross National Income (GNI), position that the country has maintained for the last five consecutive years (WAM, 2018). Taking a look at the UAE's historical and cultural roots will allow to understand the reason behind UAE's standing since these are some of the main factors that shaped the UAE's Foreign Policy and Foreign Assistance Policy.

In addition, the current status of UAE's cooperation to International Development and its contributions to the Sustainable Development Goals (SDGs) will 
also be paramount to understand the current status of the relations with the Caribbean region. The UAE-Caribbean cooperation relations have mainly expanded in the sector of renewable energy sources; however, they do not restrict to this sector only and extend to many other areas linked to Sustainable Development Goals (SDGs) such as the eradication of poverty and hunger, access to education, among others.

Revising the challenges faced by the Caribbean region and the current status of the relations UAE-Caribbean will allow to have a better understanding on the prospects for future collaboration aiming at the strengthening and advancement of bilateral relations.

\section{UAE's Contribution to ODA}

For five years in a row, from 2013-2018, the UAE's ODA as a proportion of its Gross National Income (GNI) exceeded the international target of 0.7 percent, providing 1.22 ODA/GNI on average. Making this achievement more pronounced, the UAE was also the largest donor in terms of ODA/GNI.

The OECD-DAC members ODA/GNI average during this four-year period was 0.31 percent. Of the 30 -member OECD-DAC, seven donor governments (Denmark, Germany, Luxembourg, the Netherlands, Norway, Sweden, and the United Kingdom) have met the 0.7 percent ODA/GNI, since the United Nations (UN) set the target in 1970.

Complementing these efforts, the UAE was also the first non-DAC member to meet and overachieve the same global benchmark and target. In 2016, the UAE ranked number one globally in terms of ODA/GNI, providing 1.12 percent (Ministry of Foreign Affairs and International Cooperation of the United Arab Emirates, 2017b). According to the Organization for Economic Co-operation and Development (OECD), the UAE gave Dh19.3 billion worth of development assistance in 2017, making up of 1.31 percent of its national income.

As poverty rates are the highest in Least Developed Countries (LDCs), the UN had also set an ODA/GNI target to the LDCs, at $0.15-0.20$ percent. The UAE became one of the first non-DAC members to have met this target, joining the ranks of a handful of donor countries. In 2016, the UAE ODA/GNI to the LDCs reached 0.36 percent (Ministry of Foreign Affairs and International Cooperation of the United Arab Emirates, 2017b).

In the field of humanitarian assistance, the UAE is also one of the world's most generous donor countries. In terms of volume of aid in this category, although the proportion of UAE's humanitarian assistance was only nine percent of its total ODA disbursements, the UAE was ranked sixth globally in 2016. The UAE was also the largest humanitarian donor to Yemen in 2015-2016. Relative to GNI, also in 2016, and following Norway and Luxembourg, the UAE was the world's third most generous donor of humanitarian aid (Ministry of Foreign Affairs and International Cooperation of the United Arab Emirates, 2017b).

In order to understand the origin of UAE's generosity, we have to take a closer 
look at the history, culture, and religion of the United Arab Emirates since they are the main roots of its international cooperation.

\section{Cultural Influence in UAE's Foreign Policy}

The culture of this region in general and the GCC in particular, encourages cooperation, solidarity and hospitality and those principles are highly encouraged by the religion professed by most people in the region-Islam. It is worth also pointing out that the founding father of the UAE, His Highness Sheikh Zayed, was the one who set the path for UAE's international cooperation policy.

(...) "The culture into which Shaikh Zayed was born was rooted in tribal traditions (...). In Arabia, tribalism was a positive force, providing strength and social cohesion (...) (The Emirates Center for Strategic Studies and Research, 2013).

The desert nomads or Arab Bedouins had incorporated unity and collaboration as a form of survival. "Despite the harsh conditions, the Bedouin tribesmen prized freedom and independence. Yet, survival also dictated that they develop the habit of cooperation. (...) The links that joined them and held them together were intangible-no Bedouin could claim to control another. They came together freely, bound by a code of honor that underpinned every aspect of their culture" (The Emirates Center for Strategic Studies and Research, 2013).

The Bani Yas tribe, the tribe into which Sheikh Zayed was born, was divided between those who were involved in fishing and pearling, those who were settled near the oases, and those that wandered in the desert. This diversity was the basis for the modern UAE and the importance attributed by the founding father and UAE's leadership to the concepts of unity and cooperation. "This natural tendency to include rather than to exclude, to add to one's family circle, to form alliances, to build larger and more powerful groups, is deeply rooted in the character and practice of all the desert Arabs" (The Emirates Center for Strategic Studies and Research, 2013).

“(...) the capacity of the Arab family to bind within it those from the outside is ultimately allied closely to the desert customs of honor including hospitality, generosity, sanctity of the guest, chivalry and courage" (The Emirates Center for Strategic Studies and Research, 2013).

"Shaikh Zayed always looked beyond the borders of a single nation (...) $\mathrm{He}$ advocated integration and Arab solidarity as a basis for development and progress in the Gulf and other Arab states (...). He used the notions of unity and federation as a means to bind the disparate Trucial States into a single nation, the United Arab Emirates. (...) and he saw Muslim cooperation as a reflection of the universal concepts of brotherhood advocated by Islam" (The Emirates Center for Strategic Studies and Research, 2013).

\section{Foreign Policy of the UAE}

Since its foundation in 1971, the United Arab Emirates has adopted a foreign 
policy that has been characterized by wisdom, moderation, balance and support for rights and justice, based on the foundations of dialogue and understanding between countries, respect for international treaties, adherence to the United Nations Charter, respect for the rules of good neighborliness and the leadership of other countries and the integrity of their territories, non-interference in the internal affairs of other countries and the peaceful resolution of conflicts (National Media Council, 2016).

The United Arab Emirates believes in the values of justice, international law, human rights and the provision of a happy environment for its citizens and residents. This belief emanates from realistic policies that stress that real development must include more than economic growth. It is also necessary to invest in the people, based on the values of tolerance and acceptance of others, gender equality and the like. Other policies deal with the empowerment of women, protecting the country, guarding it against extremism and sectarianism, protecting its institutions and ensuring its stability (National Media Council, 2016).

The principles guiding UAE foreign policy were expressed by the country's first President, HH Sheikh Zayed bin Sultan Al Nahyan. Sheikh Zayed's principles included an underlying belief in justice in international dealings between states, a principle of noninterference in the internal affairs of other states and the pursuit, wherever possible, of peaceful resolutions of disputes, with strong support for international institutions, such as the United Nations (UN) (Embassy of the United Arab Emirates Washington DC, n.d.).

Through its support for such institutions, the UAE seeks to reinforce the rule of international law, and to support the implementation of international conventions, protecting the interests of the small, the weak and the powerless. Foreign aid targeting poverty reduction, education and public health is a priority as well (Embassy of the United Arab Emirates Washington DC, n.d.).

The UAE stands firmly against extremism and terrorism in all its manifestations and is committed to the promotion of compassion, tolerance and inclusion. In order to counter terrorism, the UAE has established and hosts institutions such as the "Sawab" Center, the International Center of Excellence for Countering Violent Extremism "Hedayah", among others, promoting a culture of peaceful coexistence and tolerance.

President His Highness Sheikh Khalifa bin Zayed Al Nahyan has noted: “The prominent position and the great respect that the UAE enjoys internationally has resulted from the principles of our foreign policy, laid down by our father and leader, the late Sheikh Zayed bin Sultan Al Nahyan. Our foreign policy is based on our commitment to our Gulf, Arab and Islamic brethren, our friendship with all the countries in the world, good neighborliness, respect for the sovereignty of other countries and the integrity of their territories and noninterference in the internal affairs of other countries. The fundamental basis of our approach to our foreign policy is our commitment to resolve disputes peacefully and our adherence to the United Nations Charter and International 
Law” (United Arab Emirates National Media Council, 2016).

\subsection{International Cooperation and Foreign Assistance Policy}

On December 14, 2016, the UAE launched a five-year foreign aid strategy and is based on the UAE's commitment to support the sustainable development goals that the international community has pledged to achieve by 2030 .

The UAE Foreign Assistance Policy 2017-2021 is also consistent with the UAE Vision 2021, which was launched by H.H. Sheikh Mohammed bin Rashid Al Maktoum, Vice-President and Prime Minister of the UAE and Ruler of Dubai in 2010.

The achievement of Vision 2021 is based on four pillars (UAE Government, n.d.) as seen below:

1) United in responsibility: An ambitious and confident nation grounded in its heritage;

2) United in destiny: A strong union bonded by a common destiny;

3) United in knowledge: A Competitive Economy Driven by Knowledgeable and Innovative Emiratis;

4) United in prosperity: A nurturing and sustainable environment for quality living.

One of the ideas supporting the pillar of united in destiny is the goal to reach an Enhanced International Standing. According to these guidelines that will set the course of nation until 2021, “(...) Internationally, the nation will build on global successes in areas such as diplomacy, developmental and humanitarian aid, as well as hosting international institutions and events" (UAE Government, n.d.).

In this section, we will review the aspects related to the international cooperation and foreign assistance policy of the UAE taking into account its objectives, principles and main sectors in order to have a global understanding on the main guidelines that set the path for the country's relations with other countries and regions of the world.

According to the "UAE Policy for Foreign Assistance 2017-2021" launched by the UAE Ministry of Foreign Affairs and international Cooperation, the UAE's agenda for international cooperation includes four main elements as outlined below:

1) Effective foreign assistance that reflects UAE values and enhances UAE's reputation. The UAE is committed to helping people and communities in need, to building shared prosperity across all nations, and to promoting peace, tolerance, and stability. In doing so, the country will make a positive contribution to the international community.

2) Technical cooperation to enhance the impact of foreign assistance. In developing the country, the government and people of the UAE have accumulated a wealth knowledge and expertise that could be valuable for other developing nations as they aim to grow and prosper. This technical expertise can be as valuable as the UAE financial assistance. 
3) The active participation in the work of multilateral organizations. The UAE is an active member of numerous international organizations, both global and regional, involved in issues ranging from peace and security to economic development, from public health to bio-saline agriculture, and from renewable energy to humanitarian disaster response.

4) International initiatives and events based in the UAE. As a global hub, the $\mathrm{UAE}$ is uniquely well-placed to bring people and countries together to debate issues, to learn from each other and to collaborate on global challenges. UAE-based international initiatives and events which share a foreign assistance component include the International Renewable Energy Agency, the World Government Summit, the World Humanitarian Forum and Expo 2020.

From these four elements, we can conclude that foreign assistance is at the core of the international cooperation policy of the UAE. The "UAE Policy for Foreign Assistance 2017-2021" also introduces the purposes of UAE Foreign Assistance Policy as follows:

- To improve lives and reduce poverty in less fortunate communities.

- To promote stability, peace, and prosperity in the region.

- To build strong relationships with other countries, both those to which the UAE gives assistance and other donor countries with which the UAE collaborates.

- To foster expanded trade and investment ties with developing countries, thereby promoting economic growth in the developing world.

In all of these purposes, the desire to help others is evident and is a testament of UAE's commitment to assist others in improving their living conditions and advance the relations with nations of the world.

In addition, the Policy points out the areas of focus as follows:

- The largest share of UAE aid will be allocated to Country Partnerships for Development that are tailored to contribute to each country's development plan and implemented in close collaboration with those countries' governments.

- The UAE will create three global thematic programs in transport and urban infrastructure, government effectiveness, and empowerment and protection of women.

- Humanitarian aid will form an important part of the UAE's overall foreign assistance, and the UAE will expand on its role as a hub for humanitarian aid.

- UAE foreign assistance will seek opportunities to work with the private sector, in particular, UAE-based companies, and to encourage them to trade with and invest in developing nations.

- Technical cooperation will share UAE knowledge and experiences with other countries. The United Arab Emirates Technical Assistance Programme (UAETAP) will form a core part of its foreign assistance and international cooperation, helping partners through a combination of expert missions, training courses, customized programs and study visits. 
- The UAE will provide support to UAE organizations and charities, whose work in international aid complements that of UAE governmental donor organizations and will partner with relevant and effective international multilateral organizations.

\subsection{Current Status of UAE in Cooperation to International Development}

Even if in the first years of the union, foreign assistance was not recorded or acknowledged by internationally-recognized institutions, "the nation's culture of giving and high regard for international cooperation efforts date back more than 45 years ago and are as old as the country itself" (Ministry of Foreign Affairs and International Cooperation of the United Arab Emirates, 2017b). Therefore, taking into account this tradition of giving and then we can affirm that international cooperation and specifically foreign assistance are intrinsic to the foreign policy of the UAE.

It was not until 2009 that the UAE started to publish its annual UAE Foreign Aid Reports recording and reporting its Official Development Assistance (ODA) to the Development Assistance Committee of the Organization for Economic Cooperation and Development (OECD-DAC).

The UAE leadership believes that humanitarian work is both a moral responsibility and a duty, embodying a spirit of collaboration and synergy among peoples and nations. The value of the development assistance and humanitarian and charitable aid provided by the United Arab Emirates since it was established now amounts to around AED 173 billion (around US $\$ 47$ billion), with further assistance being provided every year, and a total of 178 countries have now benefited from the projects and programmes of the UAE's various donor institutions (National Media Council, 2016).

In 2016, the United Arab Emirates' foreign assistance amounting to AED 22.23 billion (USD 6.05 billion) supported development, humanitarian and charitable programmes in many developing countries, including 44 Lest Developed Countries (LDCs).

From 2011 to 2017, UAE's net ODA and ODA as a proportion of its Gross National Income have continuously and steadily grown. Since 2013 particularly, the country's contributions have placed it among the top donors worldwide surpassing the targets set by the UN. Please see Figure 1 on Net ODA and as a proportion of GNI from 2011-2017 (Ministry of Foreign Affairs and International Cooperation of the United Arab Emirates, 2017b).

\subsubsection{Funding Types}

Reaffirming the trend of 2014 when UAE foreign assistance was almost exclusively provided to developing countries in the form of grants, the share of grants compared to loans in 2016 saw an increase of 16 percent from 2015, when the UAE disbursed AED 11.78 billion (USD 3.21 billion) in grants. In 2016, grants made up 55\% of UAE's gross ODA while loans represented $45 \%$ of it. 


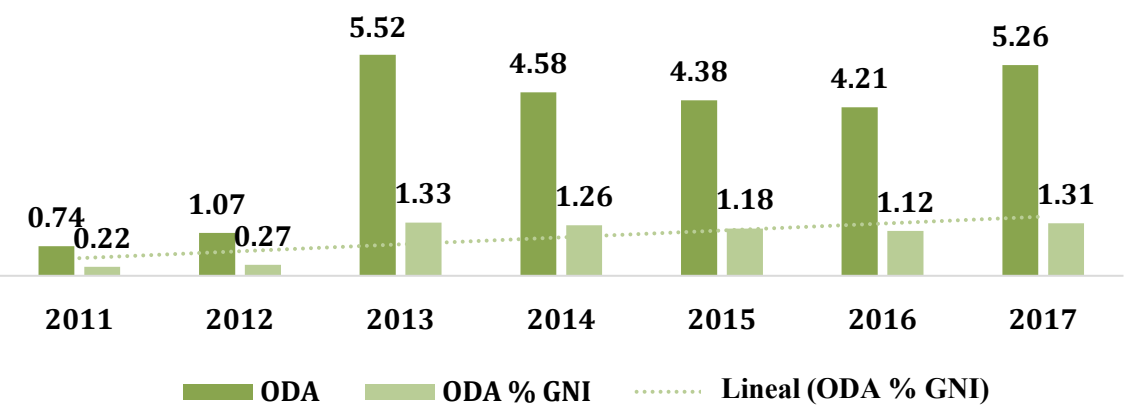

Figure 1. Net ODA in billion USD and percentage as a proportion of GNI.

\subsubsection{Aid Modalities}

Aid modality refers to the approach donors use to disburse their funds. As in previous years, the UAE chose to directly implement the majority of its foreign aid programs. From 2014-2016, more than half of UAE foreign aid projects were provided in this way.

Bilateral support to governments consistently came in as the UAE's second most preferred aid modality. Provided as unearmarked funding, this is in line with the principle on aid effectiveness, indicating "partnerships for development can only succeed if they are led by developing countries, implementing approaches that are tailored to country-specific situations and needs.

Contributions to the work of multilateral organizations, largely the United Nations, are also one of the main approaches used by the UAE foreign aid donor entities. In 2016, funds disbursed to the core budget of multilateral organizations increased, and grew by 234 percent when compared with 2015 .

According to the Organization for Economic Co-operation and Development's Development Assistance Committee (OECD-DAC), the United Nations, the World Bank and 200 other multilateral agencies and global funds receive about one-third of total Official Development Assistance (ODA). This figure rises to as much as 40 percent when funds earmarked for a particular purpose, project or country are taken into account.

With respect to the UAE, development and humanitarian programs with regional and global reach were supported largely through the country's contributions to the core budget of several multilateral organizations.

Multilateral ODA - counting only the contributions provided to support international organizations' regular core budget-accounts for only two percent of the UAE's ODA in 2016. However, these disbursements increased by 83 percent from the previous year.

Bilateral ODA, amounting to AED 16.07 billion (USD 4.38 billion) in 2016, takes into account the rest of the modalities used to disburse UAE ODA. These include: bilateral support to governments, projects implemented by the UAE donor entities, contributions to nongovernmental organizations and civil societies. It also includes contributions to the multilateral organizations that are earmarked for a particular purpose, project or country, which has seen a 132 percent rise in 2016, over 2015 ODA. 


\subsubsection{ODA Disbursements by Sector}

Determined primarily by the purpose of the foreign aid activity, the sectors of assistance provide a clear outline of the priorities and focus areas of a donor. In the case of the UAE, the priorities of its partner countries, as well as the thematic focus areas of the UAE foreign aid donor entities largely shaped its aid programming. Reflected in the UAE Foreign Assistance Policy, these sectors include humanitarian assistance, infrastructure sector, including urban development, among others (Ministry of Foreign Affairs and International Cooperation of the United Arab Emirates, 2017b).

In 2016, and consistent with its multi-year trend, the UAE placed development priorities of its partner countries at the center of its international cooperation efforts, providing more than half of foreign assistance in the form of additional funding to the general budgets of the government it supported, largely towards Egypt, Mauritania, Palestine, Somalia and Yemen. These funds were unearmarked, offering the governments greater flexibility in allocating funding according to their national development plans, from implementation of macro-economic reforms to poverty eradication programs (Ministry of Foreign Affairs and International Cooperation of the United Arab Emirates, 2017b).

From 2014-2016, programs towards urban development remained highly supported by the UAE, with total disbursements amounting to USD 1.49 billion. In 2016, these included infrastructure gaps such as urban development and road transport infrastructure programs. Similarly, efforts towards health, education, and renewable energy were largely directed to building and rehabilitation of these sectors' physical infrastructure (Ministry of Foreign Affairs and International Cooperation of the United Arab Emirates, 2017b) (Figure 2).

The UAE allocated 91 percent of its ODA in 2016 towards development programs. The reminder helped advance UAE's humanitarian and relief assistance to vulnerable countries and communities in need, mostly for long-term efforts in humanitarian situations such as emergency food aid and multi-sector support. ODA disbursements towards the emergency education sector have more than
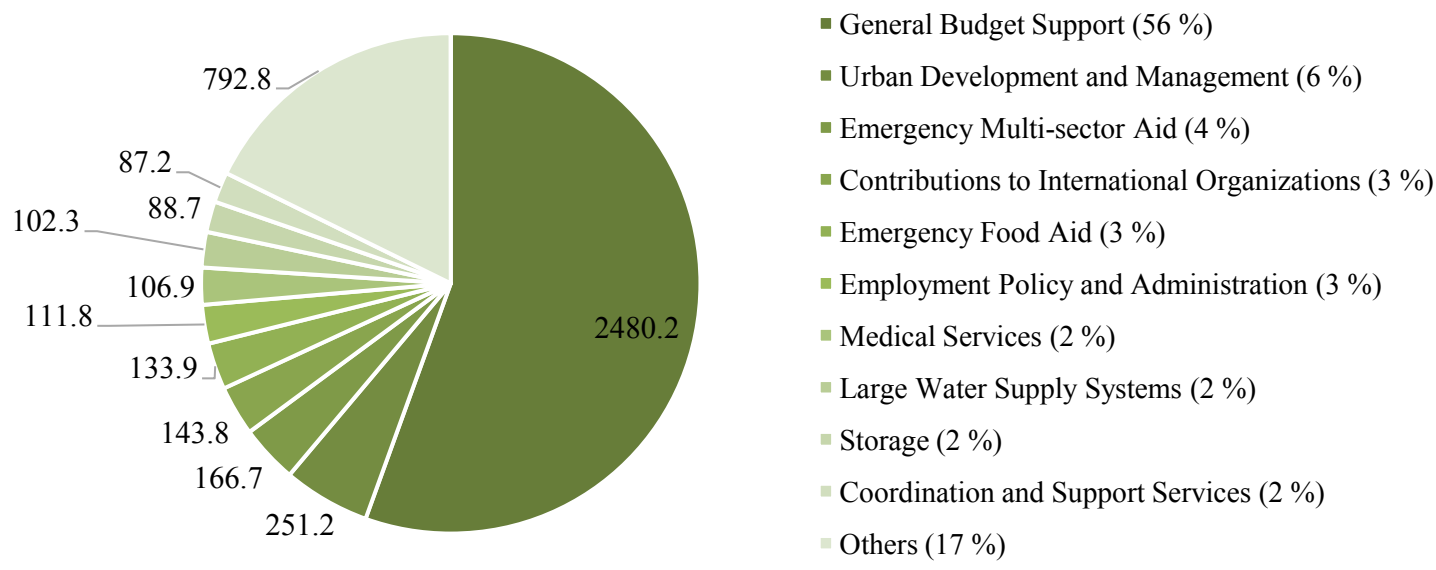

Figure 2. ODA disbursements by sector in USD million and as a percentage of total (2016). 
tripled in 2016, when compared with 2015 (Ministry of Foreign Affairs and International Cooperation of the United Arab Emirates, 2017b).

\subsubsection{Geographical Focus of UAE Assistance}

In 2016, UAE foreign assistance reached many corners of the world. Continuing a pattern from previous years, the African continent received the lion's share of the UAE's official and non-official aid during 2016, amounting to US\$3468.8 million, $57 \%$ of the total aid disbursed. The African continent was followed by Asia, Europe, Oceania and the Americas (see Figure 3 on Funds disbursed by continent and region).

More than two thirds of UAE foreign assistance were directed to support developing countries in Africa from 2014-2016. Although countries in Asia received less in terms of proportion, UAE foreign aid disbursements to Asia increased by 13 percent in 2016 when compared with 2015.

In 2016, disbursements to multi-country programmes also increased when compared with 2015; this 236 percent growth was largely due to the increase in funding support towards multilateral organizations.

\subsubsection{By Income Level}

Reports indicate that more than 70 percent of those suffering from extreme poverty live in middle-income countries. The United Nations' 2015 Report on Global Hunger shows that Lower-middle-Income Countries (LMICs) account for over half the hungry people in the world. 65 Accordingly, and as in previous years, the UAE directed more than half of its ODA disbursements in 2016 to support LMICs, with Egypt, Morocco and Syria receiving more than 95 percent of UAE funding to this group. This support translates to disbursements amounting to AED 8.47 billion (USD 2.31 billion).

Although Least Developed Countries (LDCs) have made considerable progress in mobilizing domestic resources to fund their development priorities, ODA is an important source of development financing for LDCs.

The Organization for Economic Co-operation and Development (OECD, 2018), reported that LDCs show the highest dependency on ODA, representing 68 percent of LDCs' total external finance. Complementing global efforts to support LDCs where poverty rates are highest, the UAE's share of ODA to LDCs in 2016 reached 28 percent, and has increased by four percent over 2015 disbursements. Extended to 44 LDCs, these contributions amounted to AED 4.59 billion (USD 1.25 billion).

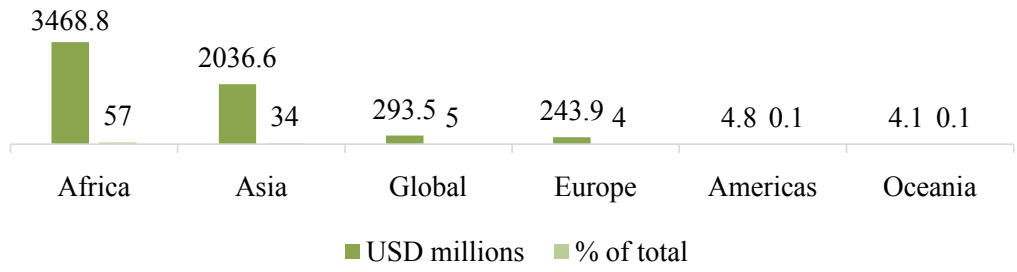

Figure 3. Funds disbursed by continent and region (in USD millions and as a percentage of total (2016). 
Mauritania, Somalia and Yemen were the UAE's top three supported LDCs in 2016. See Figure 4 on UAE 10 Main Recipient Countries of ODA (in USD billions, 2016).

\section{Supporting the Sustainable Development Goals (SDGs)}

In September 2015, at the United Nations, world leaders established the Sustainable Development Goals, an agenda for reducing poverty, improving lives and putting the world on a sustainable path and setting the year 2030 as the deadline.

The UAE made significant contributions to the deliberations that led to the SDGs. His Highness Sheikh Abdullah Bin Zayed Al Nahyan, Minister of Foreign Affairs and International Cooperation, participated in the UN's processes that determined the decision for developing SDGs, based on the 2012 recommendation of the UN Secretary-General's High-Level Panel on Global Sustainability (GSP). The UAE was also a member of the 30-member UN Open Working Group which developed the SDGs (Government of the United Arab Emirates, 2017).

The UAE's foreign assistance policy aims at contributing to global efforts to achieve the SDGs. Its assistance will be particularly directed towards eight of them, shown below (Ministry of Foreign Affairs and International Cooperation of the United Arab Emirates, 2017a):

- Goal 1: End poverty in all its forms everywhere;

- Goal 4: Ensure inclusive and quality education and promote lifelong learning;

- Goal 5: Achieve gender equality and empower all women and girls;

- Goal 8: Promote inclusive and sustainable economic growth, employment and decent work for all;

- Goal 9: Build resilient infrastructure, promote sustainable industrialization and foster innovation;

- Goal 10: Reduce inequality within and among countries;

- Goal 16: Promote peaceful and inclusive societies and build effective, accountable and inclusive institutions at all levels;

- Goal 17: Revitalize the global partnership for sustainable development.

In 2016, the first year of the implementation of the 15-year SDGs, the UAE quantified its efforts towards each of the 17 goals that contribute to global poverty eradication and sustainable development. This support corresponds to USD 6.05 billion in foreign aid disbursements.

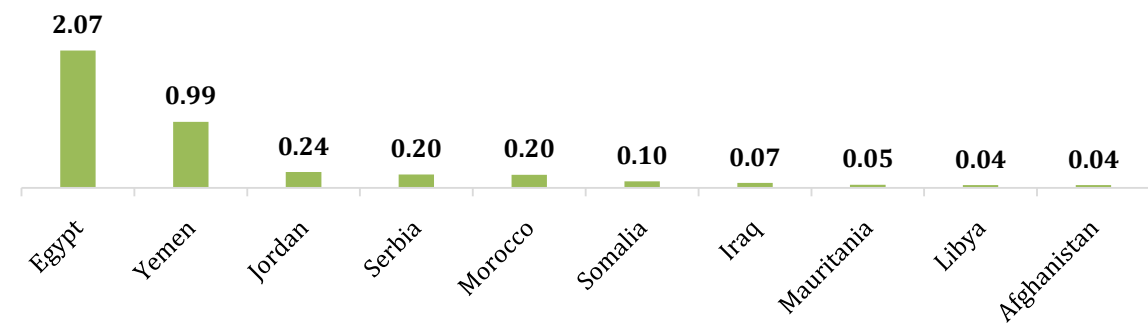

Figure 4. UAE 10 Main Recipient Countries of ODA (in USD billions, 2016). 
The UAE's top three supported SDGs in 2016 were SDG 1-No Poverty; SDG 8-Decent Work and Economic Growth; and SDG 17-Partnerships for the Goals, which altogether accounted for nearly 70 percent of the total. Please find below graph on UAE Assistance to SDGs (Figure 5).

\section{Review of UAE Contributions to SDGs}

In 2016, the three SDGs that received more funds were SDG 8 (Decent Work and Economic Growth), SDG 17 (Partnerships for the Goals) and SDG 1 (No Poverty) which altogether received USD 4.14 billion. In addition, one-third of this amount went to support 32 Least Developed Countries (LDCs).

\section{1) UAE contributions to SDG 8}

Taking into account the many challenges faced by the Middle East and North Africa (MENA) which have had a negative impact on the economic growth and opportunities regionally, most aid provided by the UAE to SDG 8-more than 95 percent-was allocated to the regional countries.

Most of the aid was aimed towards multi-pronged programmes such as supporting the budget of governments, promoting micro and small-sized entrepreneurship, and providing income-generating opportunities.

Encouraging decent work and economic growth is highly related to the support to partner countries in their development priorities as stated in the UAE's Foreign Assistance Policy. Also supporting SDG 8, UAE projects towards this sector encouraged the development of small and medium-sized enterprises, including support to the Egypt Network for Integrated Development (ENID), a joint programme of the government of Egypt and the United Nations Development Programme (UNDP). The initiative aims to promote local economic development and address rural-urban disparities in poverty and economic opportunities in Upper Egypt, while also providing income-generating opportunities, enhanced knowledge management and networking.

\section{2) UAE contributions to SDG 17}

The UAE recognizes the importance to work together to implement the 2030 Agenda which is why it builds global partnerships to accomplish sustainable development for all. Whether country-specific, regional or global, the UAE works closely with its partners to achieve the intended goals.

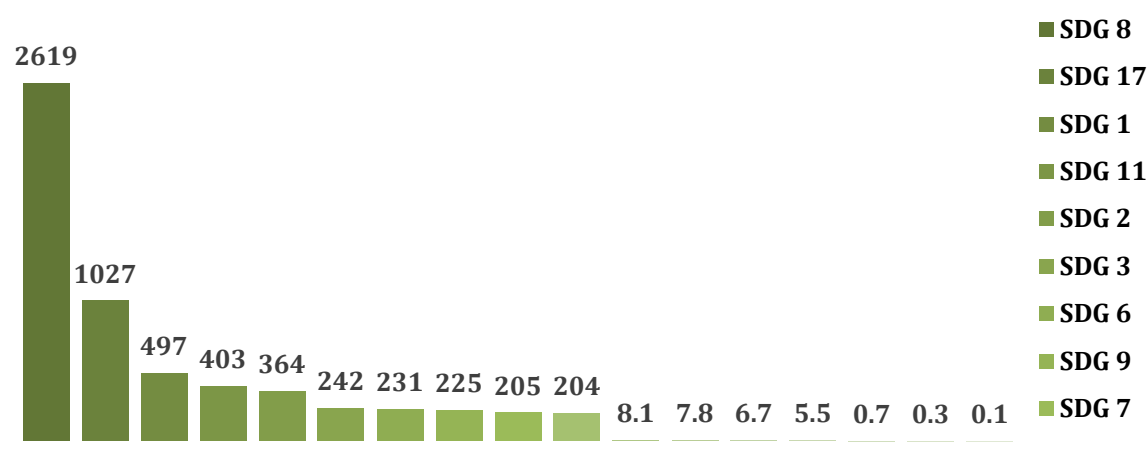

Figure 5. UAE Assistance to SDGs (in USD millions, and as \% of total, 2016). 
Under SDG 17, the majority of assistance (80 percent or AED 3.02 billionUSD 821.5 million) was provided as bilateral assistance, largely towards government budgets of a number of LDCs.

UAE partnerships with multilateral organizations play a vital role in allowing the UAE to support global issues the 2030 Agenda is concerned with. To this end, the UAE supports international organizations working across social, economic, and environmental spectrums, which in turn support various components of the UAE Foreign Assistance Policy.

In other cases, SDG 17 was supported by contributions disbursed by the UAE to fund the core budget of a number of international organizations amounting to USD 87.6 million. These included Development Finance Institutions such as the Islamic Development Bank (IDB), Arab Monetary Fund (AMF), and World Bank (WB); humanitarian funds and organizations such as the Central Emergency Response Fund (CERF) and the International Committee of the Red Cross (ICRC); and development-focused funds and organizations such as the World Trade Organization (WTO) and the UN Fund for South-South Cooperation.

\section{3) UAE contributions to SDG 1}

SDG 1 sets specific targets on eradicating poverty and ensuring social protection measures are in place to support the most vulnerable. UAE foreign assistance tackled poverty and alleviated suffering by addressing a number of social and economic needs through a range of initiatives. These included provision of humanitarian and stabilization efforts, as well as supporting families in need, orphans, and disabled people in the least developed, low and middle-income countries including conflict-affected areas, such as Iraq, Palestine, Syria and Yemen.

The UAE provided relief operations in a number of humanitarian situations in 2016. These multi-sector emergency activities received 41 percent of the total UAE foreign assistance under SDG 1 (USD 206.4 million). This included providing relief efforts to the two humanitarian crises in Syria and Yemen, as well as floods affecting Sri Lanka and Sudan, amongst others.

A good proportion of the remaining UAE contributions towards SDG 1 supported development and charitable initiatives such as provision of in-kind goods and services, and supporting vulnerable and at-risk groups.

Underprivileged families in over 23 countries were also supported by receiving small-scale production units, enabling them to generate an income, sustain livelihoods, and become more resilient during economic and social hardships.

More than 65,000 orphans were supported globally in over 20 countries through provisions for food, clothing, education, health, and other financial support. A number of orphanages were also built, and assistance was provided to cover operating, maintenance and other service costs.

UAE foreign aid donor entities also bought items that enabled the poor to generate an income. This included grain mills in Niger, dairy cows in Djibouti, and sewing machines in Sri Lanka. Empowerment to bring about change elevates 
dignity, overall well-being and hope for a better future after all.

4) Main outcomes of UAE's contributions to other SDGs

Some of the most notable results of UAE Assistance to other SDGs are the more than $800 \mathrm{~km}$-roads built and rehabilitated in developing countries; more than 66,500 houses; more than 4500 tons of relief items delivered; more than 11,000 tons of food aid delivered; around 1000 schools and training centers constructed, rehabilitates and equipped; more than 780 students provided with university scholarship grants; and thousands of children and young adults provided with education; 17.4 million children vaccinated against polio; more than 200 hospitals and medical facilities built, rehabilitates and equipped; $2650 \mathrm{~kW}$ solar power projects supported; and power supply installed in 70 villages in off-grid areas (Ministry of Foreign Affairs and International Cooperation of the United Arab Emirates, 2017b).

\section{Main Challenges Faced by the Caribbean Region}

The Caribbean region faces a number of challenges mainly derived from its high exposure to natural disasters such as hurricanes and tropical storms and from its vulnerability. Given their location in the world's second most hazard-prone region, building resilience is key to the sustainable development of the Caribbean nations and to their economic growth.

Sustainable development encompasses all pillars; therefore, building Caribbean resilience also entails meeting key challenges in the environmental sphere. Among the most pressing of these in the subregion are adapting to climate change, and reducing the impact of disasters through preparedness, recovery and sustainable reconstruction that considers the different needs of its population (Economic Commission for Latin America and the Caribbean (ECLAC, 2018).

Another aspect that continues to have a major role in the regional sustainable development is the expansion of the renewable energy sources. "The majority of Caribbean economies are totally dependent on imported fossil fuels to power economic and social activities. In an effort to mitigate greenhouse gas emissions and offset energy price shocks, many countries have started to implement renewable energy programmes, with renewable energy targets ranging from a $10 \%$ share up to $85 \%$ of the energy matrix by 2030 " (Economic Commission for Latin America and the Caribbean (ECLAC, 2018).

The high dependence on tourism as the major industry and one of the main contributors to GDP is another challenge since it is subject to external shocks such as natural disasters, economic crisis, among others. “(...) the dependence of Caribbean economies on their coastal and marine resources is among the highest in the world. In 2016 alone, the travel and tourism sector in the Caribbean contributed US $\$ 56.4$ billion to the subregion's GDP (14.9\%) and $13.4 \%$ of total employment".

In addition to that, Caribbean economies continue to face fiscal challenges 
and a high debt burden, which remains among the highest in the world relative to the size of its economies, that continue affecting their economic growth. "The perception in the capital markets of SIDS as high-risk has recently spread to the international banking system with the termination or restriction of correspondent banking services to several Caribbean small States, threatening their exclusion from the global banking system" (Economic Commission for Latin America and the Caribbean (ECLAC, 2018).

Regional countries also face constraints in accessing international cooperation funds and grants. "Caribbean small States have been classified as middle-income countries, which greatly limits their access to bilateral and multilateral grants and other concessional funding. At the same time, as small vulnerable economies, many Caribbean States have great difficulty accessing international capital markets and region forced to borrow on onerous terms" (Economic Commission for Latin America and the Caribbean (ECLAC, 2018).

"The heavy reliance of Caribbean economies on public investment to fund infrastructural development has meant that with the subregion's reduced fiscal space, investment in key infrastructure linked directly to productivity and competitiveness has not kept pace with sub-regional needs. (...) According to the CARICOM Strategic Plan 2015-2019, the development of the subregion's air and maritime infrastructure and services will be vital for improving the accessibility and mobility of people and goods and for enhancing competitiveness. A recent Caribbean Development Bank study, which assessed a cross section of Caribbean ports, found that only 4 of 12 countries had port infrastructure that was adequate, or better. The others were either in a poor state with immediate need of reinvestment or were ports with poor layout of their infrastructure" (Economic Commission for Latin America and the Caribbean (ECLAC, 2018). Therefore, tackling these infrastructural deficiencies will be critical to reducing the costs of commerce, making service delivery efficient and improving productivity and competitiveness.

According to the ECLAC report, gender inequality is another challenge that persists in Caribbean societies and that limits the full human potential of all Caribbean men and women and their access to equal opportunities. Another defy highlighted in the report is insecurity and lack of safety as several countries in the subregion are affected by high rates of crime and violence.

\section{UAE's Support for SDGs Accomplishment in the Caribbean}

The growing UAE-Caribbean relationship extends to a number of sectors and areas ranging from politics to culture. Each year has recorded the growth of exchanges in the international arena and across all levels.

One example of the UAE's desire to strengthen the relations with the Caribbean nations was the hosting in November 2018 of the First UAE-Caribbean Cooperation Forum which counted with the participation of high-level government representatives and the private sector from the UAE and the 16 Caribbean 
SIDS as well as the CARICOM and the ACS.

On the first day of the UAECCF, H.E. Reem bint Ebrahim Al Hashimy, Minister of State for International Cooperation, said: "The two oceans between us are not the barrier they once were, and we are bringing fresh eyes and enthusiasm to each other's markets and aspirations. We're especially pleased to join forces under the UAE-Caribbean Renewable Energy Fund, which can simultaneously drive achievement of the Paris climate agreement and the Sustainable Development Goals (Masdar, 2017)."

One of the highlights of the cooperation of the UAE with the Caribbean has definitely been its contribution to the accomplishment of Goal 7 which calls for greater access to affordable and clean energy through the launch of the UAE-Caribbean Renewable Energy Fund (UAE-CREF).

This partnership resulted from the government's keenness to boost bilateral relations between the UAE and the Caribbean island countries, the vast untapped renewable energy potential which can provide far-reaching benefits in terms of costs, resilience and from the desire to drive sustainable economic and social development. The initiative also celebrates the similarities shared by both the UAE and the Caribbean such as high potential for solar energy and the willingness to diversify their energy matrix.

The primary objective of this bilateral cooperation is to support renewable energy projects across 16 Caribbean countries: Antigua \& Barbuda, Bahamas, Barbados, Dominica, St. Vincent and the Grenadines, Belize, Cuba, Dominican Republic, Grenada, Guyana, Haiti, Jamaica, St Kitts and Nevis, St. Lucia, Suriname, and Trinidad and Tobago; across different cycles.

The fruits of this partnership are already visible. Recently, the countries of The Bahamas, Barbados and Saint Vincent and the Grenadines inaugurated their projects under the Fund, setting the leading pace of a brighter renewable energy future to come. Altogether, the three projects, which broke ground in November 2018, will deliver 2.35 MW of solar and $637 \mathrm{kWh}$ of battery storage capacity, while displacing more than 2.6 million tons of carbon dioxide annually. In total, diesel savings will count for more than 895,000 liters per year, worth approximately US\$1.1 million. Responding to the need to increase the resilience of Caribbean energy grids, the three projects are also designed to withstand up to 160 miles per hour winds and extreme weather, following a new requirement introduced in the UAE-CREF in the wake of Hurricanes Irma and Maria.

Another ongoing initiative which has benefited the expansion of this sector in the Caribbean is the USD 15 million ADFD-IRENA Project Facility. Resulting from this initiative, Cuba and Saint Vincent and the Grenadines were two of the selected countries in 2015 (Second cycle) and Antigua and Barbuda was selected as part of third cycle.

However, the support extended by the UAE to SDGs accomplishment in the Caribbean does not restrict only to Goal 7. As part of its contributions to the Goal 2-Zero Hunger and SDG Goal 4-Quality education, the UAE supported 
a school feeding program in St. Vincent and the Grenadines with a USD 500thousand contribution that would benefit 2139 school children with monitored school feeding across 12 primary schools. Another programme that adds to Goal 4 is the "Renovation of Villa Primary School in Antigua and Barbuda" aimed at improving the physical environment and infrastructure at the school, benefitting 355 school children.

On the same path, the UAE is supporting a number of projects together with UNICEF, UNDP and PAHO which will contribute to children's wellbeing, health, education, infrastructure and sustainability in Cuba, Jamaica, and Haiti.

\section{Conclusion}

The UAE through its Foreign Policy, Foreign Assistance Policy and international cooperation effort has proved its commitment to SDGs and ODA and its readiness to assist in natural disasters and humanitarian relief efforts.

In the case of its cooperation relations with the Caribbean nations, much has been done but there is much more to be accomplished. There are many examples of successful partnerships, but there are other sectors, programmes, and initiatives with potential to continue strengthening the bilateral relations.

Although, the collaboration in the renewable energy sector is high and ongoing, it has to remain one of the key sectors for collaboration and expand even more given the importance of the area to address many of the challenges faced by the Caribbean region.

The UAE Technical Assistance Program (UAETAP), for example, could be used to expand on the current relations. Providing technical assistance in core areas where the UAE has gained know-how throughout the years and that happen to coincide with many of the challenging areas to the Caribbean countries, the UAETAP has identified as the areas of focus the following: Mobility and Infrastructure Development, Energy and Sustainability, Government Effectiveness, Services (Finance, Freezones, Telecoms, and Tourism), and Women and Girls Empowerment. The UAETAP could be an opportunity to look at by the Caribbean nations seeking to learn from the UAE's experience, having in mind that the learning process will be reciprocal and that the UAE will also benefit from the Caribbean nations' experience.

On the other hand, the UAE will continue unlocking opportunities through its partner countries, regional organizations and regional UN agencies, among others, to pursue its goal of helping Caribbean countries achieve the SDGs and their national development plans. Strengthening coordination and collaboration with regional organizations such as the ACS will allow to evaluate new opportunities for collaboration. The future holds many promising avenues to increase the current collaboration and the UAE's government has the willingness to pursue them.

Further research on this subject will allow to present a comprehensive proposal of collaboration that will make the governments of the UAE and the Ca- 
ribbean fully aware and knowledgeable on the mutual benefits that their partnership may bring about. Such a proposal will also result in more accurate government policies and will provide a framework for further coordination between the UAE and the Caribbean.

\section{Conflicts of Interest}

The authors declare no conflicts of interest regarding the publication of this paper.

\section{References}

Economic Commission for Latin America and the Caribbean (ECLAC) (2018). The Caribbean Outlook. Santiago: United Nations.

Embassy of the United Arab Emirates Washington DC (n.d). Foreign Policy. https://www.uae-embassy.org/about-uae/foreign-policy

Government of the United Arab Emirates (2017). From Goals to Reality: UAE and the 2030 Agenda for Sustainable Development.

Masdar (2017). Masdar News.

https://news.masdar.ae/en/news/2018/11/28/09/55/uae-caribbean-renewable-energy-fu nd-announces-major-projects-in-five-countries-23

Ministry of Foreign Affairs and International Cooperation of the United Arab Emirates (2017a). Promoting Global Prosperity and Peace UAE Policy for Foreign Assistance 2017-2021.

Ministry of Foreign Affairs and International Cooperation of the United Arab Emirates (2017b). United Arab Emirates Foreign Aid 2016. Abu Dhabi.

National Media Council (2016). United Arab Emirates: An introduction to its origins and phases of development in various spheres of life. National Media Council. Obtenido de National Media Council.

http://nmc.gov.ae/en-us/E-Participation/Lists/Publications/Attachments/1/E-Printing \%20English\%20Inside.pdf

OECD (2018). Development Co-Operation Report 2018: Joining Forces to Leave No One Behind. Paris: OECD Publishing. https://doi.org/10.1787/dcr-2018-en

The Emirates Center for Strategic Studies and Research (2013). With United Strength-H.H. Shaikh Zayid Bin Sultan Al Nahyan The Leader and the Nation. Abu Dhabi: The Emirates Center for Strategic Studies and Research.

UAE Government (n.d.). UAE Vision 2021.

https://www.vision2021.ae/en/uae-vision

WAM (2018). UAE Is World's Top Donor for Fifth Year. Gulf News. https://gulfnews.com/uae/government/uae-is-worlds-top-donor-for-fifth-year-1.22027 $\underline{84}$ 